\section{Micro-CT Evaluation of Root Filling Removal after Three Stages of Retreatment Procedure}

Ricardo Abreu da Rosa' ', Manuela Favarin Santini', Bruno Cavalini Cavenago², Jefferson Ricardo Pereira ${ }^{3}$, Marco Antônio Húngaro Duarte ${ }^{2}$, Marcus Vinícius Reis Só ${ }^{1}$
'Department of Conservative Dentistry, UFRGS - Universidade Federal do Rio Grande do Sul, Porto Alegre, RS, Brazil ${ }^{2}$ Department of Endodontics, Dental School of Bauru, USP - Universidade de São Paulo, Bauru, SP, Brazil ${ }^{3}$ Department of Prosthodontics, Dental School, UNISUL Universidade de Santa Catarina do Sul, Tubarão, SC, Brazil

Correspondence: Marcus Vinícius Reis Só, Rua Ramiro Barcelos, 2492, 90035-003 Porto Alegre, RS, Brasil. Tel: +55-51-3308-5357. e-mail endo-so@hotmail.com

Key Words: endodontics, maxillary molars, retreatment, micro-computed tomography.

\section{Introduction}

Persistent apical periodontitis is primarily caused by intracanal microorganisms that survive primary root canal treatment. Thus, nonsurgical endodontic retreatment is indicated to remove filling material from the root canal and to regain access to the apical foramen. Such procedure can be accomplished with hand, rotary and ultrasonic instruments $(1,2)$, with or without solvents and heat to facilitate the procedure (3). However, it is almost impossible to remove gutta-percha or endodontic sealer completely from root canals, irrespective of the retreatment technique $(1,2)$. The majority of $\mathrm{Ni}-\mathrm{Ti}$ instruments were initially developed for root canal preparation, while some systems were developed only for retreatment. The ProTaper Universal Retreatment System (PTR) (Dentsply Maillefer, Ballaigues, Switzerland) consists of three instruments for use in each third of the root canal: D1 - 30/.09, $16 \mathrm{~mm}$; D2 - 25/.08, $18 \mathrm{~mm}$; and D3 - 20/.07, $22 \mathrm{~mm}$. The D1 file presents an active tip to facilitate its penetration into the filling material (4). These files present convex triangular cross-sections similar to those of the ProTaper shaping and finishing files (4).

After using retreatment systems, the amount of residual filling material must be further reduced by apical enlargement beyond the initial preparation size (5). Regardless of the instrument, kinematics or retreatment technique studies have reported the presence of filling residues on the canal walls (6-9). The amount of the residues can be reduced when canal enlargement during retreatment exceeds the initial preparation size (5). Different authors, $(2,5)$ have emphasized the critical importance during retreatment of canal enlargement by at least two sizes beyond the filled canal size. Additional enlargement could reduce the amount of residual filling even further. However, extensive enlargement is associated with the risk of canal transportation, and this risk has to be carefully weighed against the added benefit.

Rotary instruments and reciprocating files can also be used for this purpose. Recently, WaveOne (Dentsply Maillefer) was designed to be used with a dedicated reciprocating motion motor. It consists of three single-use files: Small (ISO 21 tip and 6\% taper) for fine canals; Primary (ISO 25 tip and 8\% taper) for the majority of canals; and Large (ISO 40 and 8\% taper) for large canals (10). Rios et al. (6) stated that reciprocating systems are as effective as PTR instruments; on the other hand according to Zuolo et 
al. (7), reciprocating instruments remove greater amounts of filling from root canals than rotary files. The capability of removing filling material of WaveOne and PTR is similar, but WO achieved its goal faster than PTR (9). Martinho et al. (8) clinically compared the ability of reciprocating and rotary systems in disinfecting root canals. After accessing thirty endodontically treated teeth with apical periodontitis the authors observed that reciprocating instruments were as effective as the ProTaper system for removal of endotoxins and bacteria in endodontic retreatment. Ultrasonic tips have been used in endodontics for many purposes, including to remove fractured files, intraradicular posts or calcifications from the pulp chamber, to activate the irrigant or to prepare and re-prepare root canals (11). When used to activate the irrigant without simultaneous instrumentation, the ultrasonic action is called passive ultrasonic irrigation (PUI) (11).

PUI has been used to remove smear layer, debris and root canal dressings $(12,13)$. A recent study (14) found that use of xylene and PUI after mechanical instrumentation enhanced removal of filling materials from anatomically complex teeth. On the other hand, Fruchi et al. (15) reported that the use of xylene with PUI promoted a little increasing in removal of filling material, but it was not statically significant. Some doubts still remain regarding the efficacy of PUI and solvents in assisting filling removal $(6,14,15)$.

The aim of this study was to quantify the remaining filling material in maxillary molars canals after removal with ProTaper Universal Retreatment instruments, after re-preparation with rotary or reciprocating instruments and after PUI. The null hypotheses of this study were: (1) the volume and the canals' cross-section has no influence on the removal of the filling material; (2) there is no difference in removing the root canal filling using a rotary or a reciprocating file system; and (3) there is no difference in removing the canal filling using rotary instruments alone and rotary instruments plus PUI.

\section{Material and Methods}

\section{Selection of Teeth}

Twenty sound maxillary molars without previous endodontic treatment, cracks or root resorptions were included in this study. Additionally, only tooth with mesiobuccal and distobuccal roots that presented an angle of curvature higher than $22^{\circ}$ were included in this study. Roots with immature apices were discarded and replaced by others who meet the inclusion criteria. Initially, the external root surfaces were cleaned with periodontal curettes. Next, the crowns were removed using a low-speed diamond saw and underwater cooling (Labcut 1010; Extec Corp, Enfield, CT, USA) at the cementoenamel junction.
The glide path was verified with a \# $10 \mathrm{~K}$-file (Dentsply Maillefer) until the tip of the instrument was just visible at the apical foramen. Then the silicon stop was positioned at the reference point and the measure was recorded. The working length was established as being $1 \mathrm{~mm}$ shorter than this measure. If a second mesiobuccal canal was present, the tooth was excluded from the study and replaced by another who presented only one mesiobuccal canal.

\section{Root Canal Preparation, Filling, and Micro-CT \# 1}

All of the root canals were prepared by the same operator (R.A.R.) using ProTaper instruments with an X-Smart motor (Dentsply Maillefer) at $250 \mathrm{rpm}$ and a torque setting of up to $2.5 \mathrm{~N} / \mathrm{cm}$.

Initially, the canals were pre-flared using the SX file in the cervical third and S1 to two-thirds of the estimated WL. Next, rotary instrumentation was accomplished using $\mathrm{S} 1, \mathrm{~S} 2$, and F1 to full WL in mesiobuccal and distobuccal canals. Palatal canals were enlarged until F2 instruments. Between each file change, the root canals were rinsed with $2 \mathrm{~mL}$ of $1 \%$ sodium hypochlorite $(\mathrm{NaOCl})$, delivered with a syringe and 30-gauge needle (NaviTip, Ultradent, South Jordan, UT, USA) inserted to $2 \mathrm{~mm}$ short of the entire working length (WL). After the completion of preparation, the root canals were irrigated with a final sequence of 5 $\mathrm{mL}$ of 17\% EDTA for $3 \mathrm{~min}$ and $2 \mathrm{~mL}$ of $1 \% \mathrm{NaOCl}$. Next, the canals were dried using paper points.

Root canal filling was performed using F1 (mesiobuccal and distobuccal canals) and F2 (palatal canals) gutta-percha cones (ProTaper; Dentsply Maillefer) and AH Plus (Dentsply Maillefer). The gutta-percha cones were inserted into the canals to verify if they reach the WL and if they fit at the apical third. Subsequently, the sealer was mixed according to the manufacturer's instructions and placed in the canal using a lentulo, until the canal was full. Finally, the gutta-percha cone was slowly inserted into the canal until it reached WL. The excess of gutta-percha was removed with a heated plugger at the level of the canal orifice. The canals were sealed with a cotton pellet and temporary filling material (Cavit G; 3M-ESPE, Seefeld, Germany). The quality and apical extent of the root canal filling were assessed with buccolingual and mesiodistal radiographs. Filling was considered adequate when it appeared to be homogeneous without any voids. In cases of inadequate root canal filling, the teeth were discarded and replaced with other teeth. All of the specimens were stored for two weeks at $37{ }^{\circ} \mathrm{C}$ and $100 \%$ humidity to allow for the complete setting of the sealer.

The teeth were scanned to measure the overall root canal filling (micro-CT \# 1). Specimens were scanned using a desktop X-ray microfocus CT scanner (SkyScan 1174v2; SkyScan, Kontich, Belgium). The scanning procedures were 
performed with the following parameters: $50 \mathrm{kVX}$-ray tube voltages; $800 \mu \mathrm{A}$ anode current and voxel size of $14.4 \mu \mathrm{A}$. Four specimens were scanned at a time. Scans with $1304 \mathrm{x}$ 1024 pixels were obtained with acquisition intervals of $1^{\circ}$ over a total of $360^{\circ}$ rotation. Next, the data from micro-CT \#1 were saved for further analysis.

\section{Filling Removal and Micro-CT \#2}

ProTaper Universal Retreatment (PTR) instruments were used, at $500 \mathrm{rpm}$ and a torque setting of up to $2 \mathrm{~N} / \mathrm{cm}$, to remove root fillings by using D1, D2, and D3 retreatment instruments. These instruments have a taper/tip diameter of $0.09 / 0.30,0.08 / 0.25$, and $0.07 / 0.20 \mathrm{~mm}$, respectively. PTR instruments were used with brushing movements against the canal walls in a crown-down manner at cervical (D1), middle (D2), and apical (D3) thirds until reaching the WL as recommended by the manufacturer. After each instrument change, the canals were rinsed with $2 \mathrm{~mL}$ of $1 \% \mathrm{NaOCl}$. Finally, a new micro-CT scan (micro-CT \#2) was performed as described previously.

\section{Re-preparation and Micro-CT \#3}

After micro-CT \#2, all of the specimens were randomly divided in two groups according to the instrument used for re-preparation: ProTaper F2 for mesiobuccal and distobuccal canals and F4 for palatal canals $(n=10)$ or WaveOne Primary files for mesiobuccal and distobuccal and WaveOne Large for palatal canals $(n=10)$. For specimen preparation with ProTaper files, motor setting was maintained as described for canal preparation. WaveOne files were used in a pecking motion with the reciprocating motor (VDW GmbH, Munich, Germany). Both systems were used as recommended by the manufacturer. After reaching the working length, the instrument was removed from the root canal and a final rinse with $5 \mathrm{~mL}$ of $1 \% \mathrm{NaOCl}$ was performed. Thereafter, the canals were dried with paper points, and a new microCT scan was performed (micro-CT \#3).

\section{PUI and Micro-CT \#4}

Root canals were irrigated with $2 \mathrm{~mL}$ of $1 \%$ of $\mathrm{NaOCl}$. Then, passive ultrasonic irrigation (PUI) was performed using a smooth ultrasonic tip, size 15 , taper $0.02,25 \mathrm{~mm}$. The ultrasonic tip was coupled to the file-holding adapter of the handpiece of a NAC Plus ultrasonic unit (Adiel LTDA, São Paulo, SP, Brazil) and then passively inserted into the root canal $2 \mathrm{~mm}$ short of WL in both groups. PUI was performed at $40 \mathrm{kHz}$ for $30 \mathrm{~s}$. The PUI protocol was repeated twice always with a previous irrigation with $2 \mathrm{~mL}$ of $1 \% \mathrm{NaOCl}$ per canal (i.e. mesiobbucal, distobuccal, palatal). Attempts were made to maintain the ultrasonic tip centered into the canal during PUI. Root canals were dried with paper points and the micro-CT \#4 scan was performed.

\section{Micro-CT Measurements and Evaluations}

The sequences of scans were reconstructed using NReconv1.6.4.8 (SkyScan) software. The amount of residual filling after the stages of endodontic retreatment was volumetrically analyzed using CTscan v1.11.10.0 (SkyScan) software, individually for each canal (i.e., mesiobuccal, distobuccal and palatal). In CTan software, the four samples presented in the initial image were separated to permit individual handling and analysis. This was limited to the region of interest (ROI) for each specimen, and the new ROI data were saved in separate folders. Then, the set of sample data was opened, and the binary value was adjusted according to the raw images. Such value was recorded and then it was used as a parameter for the micro-CT \#2, micro-CT \#3, and micro-CT \# 4 scans. Finally, the 3D plug-in analysis was used to measure quantitatively the residual filling amount. This tool automatically calculates the overall volume $\left(\mathrm{mm}^{3}\right)$ from the 3D image of binary selected objects (white color). All the measurements and evaluations were performed by the same examiner, who was blinded for the stages of endodontic retreatment and for the instrument used to re-prepare the specimens.

\section{Statistical Analysis}

Statistical analysis was performed using SPSS software version 16.0 for Windows (SPSS Co., Chicago, IL, USA). Because normality assumptions could not be verified (Shapiro-Wilk test, $p<0.05$ ), data from volumetric analysis of residual filling material were statistically compared by using non-parametric tests. Kruskal-Wallis and Dunn post hoc tests were used to compare the volume of residual filling material in each canal after the four stages of the endodontic retreatment regardless of the instrument used for re-prepare. To compare the differences at each stage of endodontic retreatment in the different root canals (i.e., mesiobuccal, distobuccal and palatal), the Kruskal-Wallis test and Dunn's post hoc test were used. Differences in the volume of residual filling material among the stages of endodontic retreatment in each canal were analyzed using Friedman's test and Dunn's post hoc test. The level of significance was set at 5\% for all of the statistical tests.

\section{Results}

The amount filling material in each stage of the endodontic retreatment was similar, irrespective of the root canal assessed ( $p>0.05$ ) (Table 1). The intra-group analysis showed that the greatest reduction of filling material was observed after using ProTaper Universal Retreatment files $(p<0.05)$. After using ProTaper F2 and WaveOne Primary files, the volume of residual filling was similar to that observed after using ProTaper Universal Retreatment files $(p<0.05)$. The inter-group analysis showed that both rotary 
systems files removed similar amounts of filling material ( $p>0.05$ ). Finally, PUI did not improve the removal of filling material after using rotary or reciprocating files for root canal preparation $(\mathrm{p}>0.05)$.

Figure 1 shows 3D micro-CT scans and the canal crosssections after each stage of the endodontic retreatment in PT and WO groups.

\section{Discussion}

Recently, micro-CT was used to quantify the remaining material after different retreatment techniques $(2,16)$. Micro-CT consists of a rapid, highly accurate and nondestructive method to evaluate three-dimensionally the efficacy of endodontic retreatment. In addition, the main advantage of micro-CT imaging is that it enables repeated scans of the same specimen in different stages of retreatment (5). Therefore, due to the absence of studies assessing the ability of PUI to assist in the removal of root filling from root canals, this study aimed to quantify the residual amount of material after each stage of retreatment.

The choice for maxillary molars in this study was performed to enable the comparison of the residual filling material between the three steps of endodontic retreatment and each root canal (mesiobuccal, distobuccal and palatal). Additionally, the capability of the instrument used for re- preparation in removing filling material was also assessed. Only tooth with mesiobuccal and distobuccal roots that presented an angle of curvature higher than $22^{\circ}$ were included in this study in order to standardize the curvature angle. Moreover, the length of the roots should be more than $14 \mathrm{~mm}$ and less than $18 \mathrm{~mm}$. The specimens were undergone to a stratified randomization previously to the stage of re-preparation to not influence the procedures performed before. The stratified randomization takes in account the length and the curvature angle of the roots.

In curved canals, the removal of filling material and instrumentation are more difficult than in straight canals and these steps can constitute a challenge for the clinician. However, the majority of laboratory studies have used straight canals with round cross-section shapes to evaluate the amount of remaining root filling $(1,12)$. The current rotary files present spiral blades and helical formations that, when rotating, assume a form that presents a round cross-section (4). This aspect leads to a round preparation with substantial untouched areas, especially in flattened or oval-shaped canals (4). Due to the above-mentioned reasons, mesiobuccal, distobuccal and palatal canals from upper molars were evaluated in this study. Figure 1 presents the different canal cross-sections at $3 \mathrm{~mm}, 5 \mathrm{~mm}$, and 7 $\mathrm{mm}$ from the apex. Because it was included only maxillary

Table 1. Table 1. Median, 25th and 75th percentile values of remaining filling material ( $\mathrm{mm}^{3}$ and \%) after using ProTaper Universal Retreatment (PTR), ProTaper (PT), WaveOne (WO) files and passive ultrasonic irrigation (PUI) in mesiobuccal, distobuccal and palatal canals.

\begin{tabular}{|c|c|c|c|c|c|c|c|c|}
\hline \multirow{2}{*}{ Canal } & \multicolumn{4}{|c|}{ ProTaper F2 } & \multicolumn{4}{|c|}{ WaveOne Primary } \\
\hline & Initial & PTR & PT & PU1 & Initial & PTR & wo & PU1 \\
\hline \multicolumn{9}{|c|}{ Mesiobuccal } \\
\hline Median & $1.507^{\text {Aa }}(100 \%)$ & $0.072^{\mathrm{A}, \mathrm{b}}(4.7 \%)$ & $0.055^{\mathrm{A}, \mathrm{b}}(3.6 \%)$ & $0.050^{\mathrm{A}, \mathrm{b}}(3.3 \%)$ & $1.231^{\mathrm{A}, \mathrm{a}}(100 \%)$ & $0.077^{\mathrm{A}, \mathrm{b}}(6.3 \%)$ & $0.042^{\mathrm{A}, \mathrm{b}}(3.4 \%)$ & $0.041^{\AA, \mathrm{b}}(3.3 \%)$ \\
\hline P25 & 1.340 & 0.048 & 0.016 & 0.013 & 1.092 & 0.051 & 0.039 & 0.036 \\
\hline P75 & 1.665 & 0.168 & 0.155 & 0.132 & 1.334 & 0.220 & 0.200 & 0.185 \\
\hline
\end{tabular}

Distobuccal

$\begin{array}{ccccccccc}\text { Median } & 1.373^{\mathrm{Aa}}(100 \%) & 0.070^{\mathrm{A}, \mathrm{b}}(5.1 \%) & 0.032^{\mathrm{A}, \mathrm{b}}(2.3 \%) & 0.030^{\mathrm{A}, \mathrm{b}}(2.2 \%) & 1.164^{\mathrm{A}, \mathrm{a}}(100 \%) & 0.043^{\mathrm{A}, \mathrm{b}}(3.7 \%) & 0.023^{\mathrm{A}, \mathrm{b}}(2.0 \%) & 0.023^{\mathrm{A}, \mathrm{b}}(2.0 \%) \\ \text { P25 } & 1.172 & 0.006 & 0.002 & 0.001 & 0.922 & 0.015 \\ \text { P75 } & 1.456 & 0.200 & 0.1481 & 0.143 & 1.449 & 0.082 & 0.065\end{array}$

Palatal

\begin{tabular}{ccccccccc} 
Median & $1.641^{\mathrm{Ba}}(100 \%)$ & $0.183^{\mathrm{B}, \mathrm{b}}(11.5 \%)$ & $0.142^{\mathrm{B}, \mathrm{b}}(8.6 \%)$ & $0.142^{\mathrm{B}, \mathrm{b}}(8.6 \%)$ & $1.548^{\mathrm{B}, \mathrm{a}}(100 \%)$ & $0.231^{\mathrm{B}, \mathrm{b}}(14.9 \%)$ & $0.175^{\mathrm{B}, \mathrm{b}}(11.3 \%)$ & $0.155^{\mathrm{B}, \mathrm{b}}(10 \%)$ \\
P25 & 1.382 & 0.072 & 0.045 & 0.039 & 1.331 & 0.057 & 0.024 \\
P75 & 1.851 & 0.0428 & 0.343 & 0.239 & 2.873 & 0.892 & 0.759 \\
\hline
\end{tabular}

Uppercase letters compare each root canal in one stage of endodontic retreatment separately $(\mathrm{p}<0.05)$. Lowercase letters indicate statistically significant difference between the endodontic stages of retreatment $(p<0.05)$. 
molars who presented one canal per root, it can be noted the oval aspect of the mesiobuccal canal. Additionally, the palatal canal presents a flattened cross-section toward the buccal canals. At apical third, the mesiobuccal, distobuccal and palatal canals presented round cross-section.

The first hypothesis was rejected. Palatal canal presented the highest volume of filling material at the initial stage and also the highest volume of residual filling material after
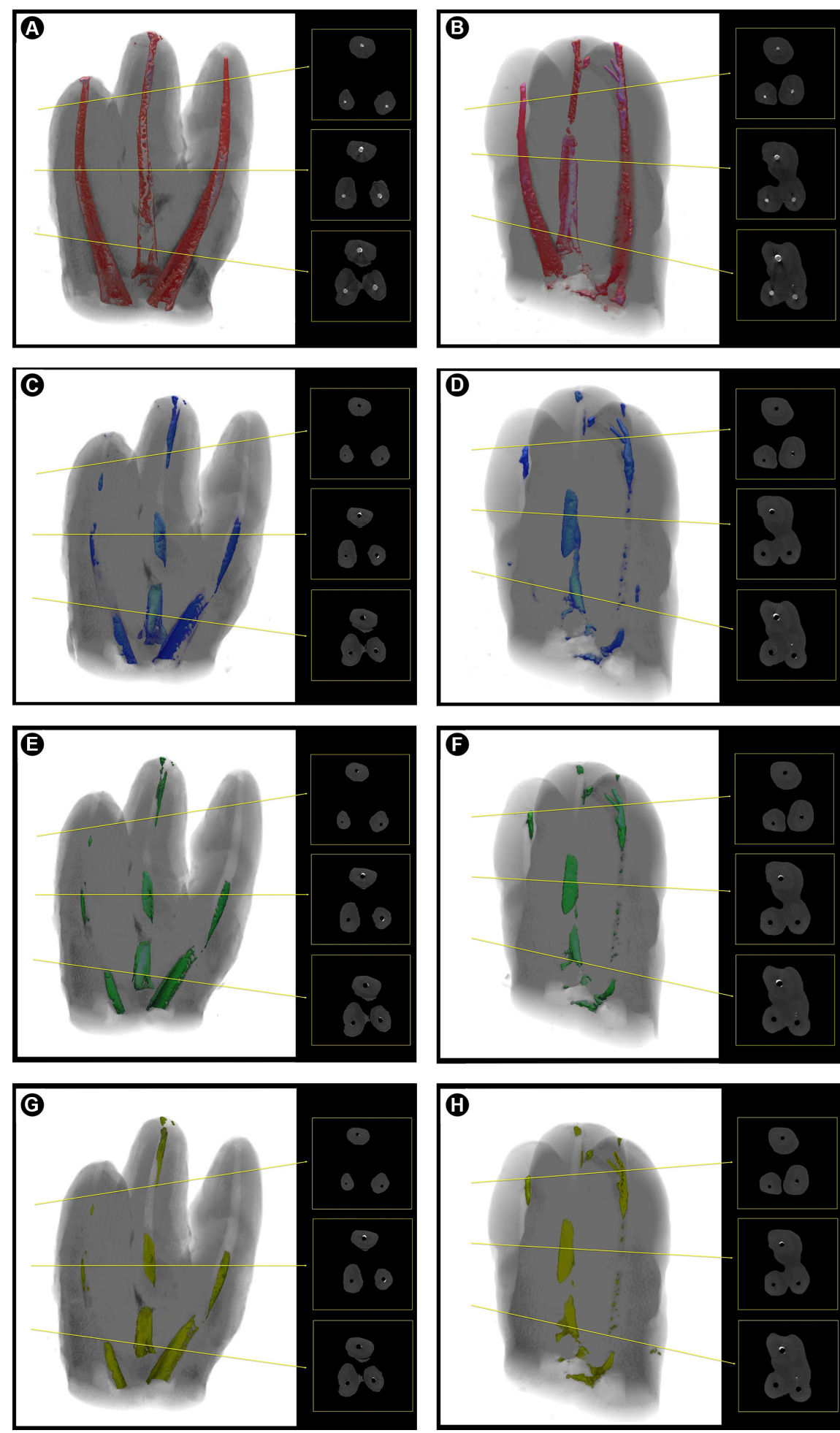

Figure 1. Micro-CT 3D scans and 2D cross-sections from mesiobuccal, distobuccal and palatal canals after each stage of the endodontic retreatment in all root levels. A,B: initial. C,D: After filling removal with ProTaper Retreatment instruments. E: After re-preparation using a rotary system (ProTaper). F: After re-preparation using a reciprocating rotary system (Wave0ne). G: After PUI in PT group. H: After PUl in WO group. 
the other stages of the retreatment. These findings agree with those of the study of Rechenberg and Paqué (16), in which filling removal was influenced by the cross-sectional root canal shape. It is likely that such an influence occurred due discrepancies among the analyzed canals (distal canals of mandibular molars and buccal and palatal canals of maxillary premolars). For the same reason, associated to the difference in initial volume of root canals, the present study presented different amounts of residual filling material when mesiobuccal, distobuccal and palatal canals were compared (Table 1). Even with further enlargement of palatal canals using ProTaper F4 or WaveOne Large instruments, better removal of filling was not achieved.

Chemical solvents (i.e., chloroform, xylol, citrol, eucalyptol, orange oil) have been used to dissolve guttapercha $(4,7)$. Microscopic and radiographic evaluations have shown that the use of chloroform does not improve the performance of hand and rotary files in removing filling material (17). Solvents promote the formation of a fine layer of softened gutta-percha, which can obliterate the sulcus, isthmus, lateral canals and any irregularities (17). Such effects can make the removal of filling material even more difficult and time-consuming, which might impair and even compromise the cleaning of the root canal system. Due to all of these reasons, filling removal was performed without using solvents, to verify the real action of the analyzed rotary and reciprocating systems. In addition, the great efficacy of rotary instruments in removing fillings eliminates the need for solvents (17). The time required to reach full working length is shorter when chloroform is used. However, less time is required to achieve satisfactory filling removal when retreatment is performed without solvent (4).

As expected, the most substantial reduction in root filling volume occurred after using the ProTaper Universal Retreatment instruments. However, the use of single files to re-prepare root canals did not reduce the amount of filling material ( $p>0.05$ ) (Table 1). Additionally, no differences in remaining filling volumes were observed after using ProTaper instruments or WaveOne files ( $p>0.05$ ) (Table 1). Therefore, the second hypothesis was accepted. The root canals must be enlarged to at least two sizes greater than the final instrument used for root canal preparation (2). In contrast, another previous study achieved satisfactory filling removal when apical enlargement was increased by only one size (from a size 30 to size 40 ProTaper instrument) in mandibular incisors (2). As the aim of this study was evaluate the efficacy of WaveOne Primary and Large files, the comparison must be made with a rotary file having similar dimensions (ProTaper F2 and F4, respectively). Thereafter, mesiobuccal and distobuccal canals were only enlarged to one size greater the final instrument used for initial preparation. Moreover, further enlargement can result in an increased risk of instrument fracture and root canal transportation, especially in curved canals (mesiobuccal) (2). Possibly, instruments 40.02 could promote few apical deviation and better filling removal. In palatal canals, the final enlargement was two sizes greater than the final instrument used for preparation because they are normally straight and present higher volume than mesiobuccal and distobuccal canals.

To date, only few studies have evaluated the efficacy of reciprocating instruments in removing root canal filling $(6,7,9,14,15)$. The results of the present study differ from a previous study (7), which observed differences between rotary and reciprocating instruments. Firstly, the authors used a $2 \mathrm{D}$ method to evaluate the residual filling material (i.e. dental operating microscope). Thus, the data were evaluated in $\mathrm{mm}^{2}$ and further transformed in percentage of the total canal area. In turn, the present study used volumetric analysis to measure the amount of residual filling material, which may have contributed for the different results. Additionally, Zuolo et al. (7) used maxillary central incisors. It is easier to remove filling in straight and wide canals than in curved and narrow canals. The amount of residual filling was not associated with the kinematics of the instruments but rather mainly with their dimensions. ProTaper F2 and F4 and WaveOne Primary and Large instruments present the same tip size ( $D 0=0.25 \mathrm{~mm}$ and $\mathrm{D} 0=0.40 \mathrm{~mm}$ ) and taper features (10). The only difference lies in the design of the cross-section and the reverse cutting blades of the WaveOne files (10). The reverse cutting blade arrangement is due to the reciprocation motion, as these instruments cut in $140^{\circ}$ clockwise motion and they release at $45^{\circ}$ counterclockwise. ProTaper files present a constant triangular convex cross-section, while WaveOne files are characterized by different cross-sectional designs over their entire lengths: cross-sections with radial lands near the tip; and a modified triangular convex cross-section in the middle and near the shaft.

The third hypothesis was confirmed. There was no difference in removing the canal filling using rotary instruments alone and rotary instruments plus passive ultrasonic irrigation. Besides, PUI improves the cleaning of root canals and the removal of intracanal dressings $(12,18)$, the same did not occur when PUI was carried out in order to improve the filling removal. The removal of intracanal dressing and debris was maximized after PUI due to the formation of acoustic microstreaming and cavitation, which occur within the root canal from the apex to the coronal third (11). Intracanal dressing and debris are easily removed after PUI because they adhere weakly to canal walls (13). The unchanged volume of filling after PUI probably occurred because the bond strength of AH Plus to root dentin is 
high (19), and its adhesion probably was higher than the forces generated by acoustic microstreaming and cavitation. Because there are few studies comparing the effects of PUI in the removal of root canal fillings, direct comparisons are difficult. Grischke et al. (20) found a superior effect of PUI over other irrigation procedures (i.e. syringe irrigation, CanalBrush, EndoActivator, and RinsEndo) on sealer removal from the surface and from simulated irregularities of root canals. Finally, the PUI was performed using $\mathrm{NaOCl}$. Further studies must be carried out to verify the influence of PUI on filling removal when the solvent is activated, such as chloroform, xylol, citrol, eucalyptol and orange oil.

Neither rotary instruments nor PUI was able to remove filling material completely from the root canal systems of maxillary molars. The greatest reduction in filling material was achieved with ProTaper Retreatment files. ProTaper and WaveOne files removed similar volumes of filling. PUI did not improve the removal of filling material achieved after re-preparation with rotary and reciprocation files.

\section{Resumo}

0 objetivo dente estudo foi quantificar o material obturador residual após remoção da obturação, repreparo do canal com instrumentos de rotação . contínua e reciprocantes e após irrigação ultrassônica passiva (IUP). Vinte $\approx$ molares superiores foram preparados usando instrumentos ProTaper sequencialmente até F1. Os dentes foram obturados com AH Plus e cones de guta percha ProTaper utilizando a técnica de cone único. Em seguida, os espécimes foram submetidos à microtomografia computadorizada (Micro-

CT \#1). Então, o material obturador foi removido utilizando instrumentos ProTaper Retratamento e novo escaneamento foi realizado (Micro-CT \#2). Os espécimes foram divididos em dois grupos de acordo com o instrumento usado para o repreparo: de rotação contínua (ProTaper) ou reciprocante (WaveOne) (Micro-CT \#3). Finalmente, IUP foi realizada e nova micro-CT foi conduzida (Micro-CT \#4). As análises intra-grupo e inter-grupos foram realizadas utilizando os testes de Friedman e de Dunn e o teste de KruskalWallis e Dunn, respectivamente. 0 canal palatino apresentou o maior volume de material obturador remanescente em todos os estágios do tratamento endodôntico $(p<0,05)$. A maior redução do volume da obturação foi obtida após usar os instrumentos ProTaper Retratamento $(\mathrm{p}<0,05)$. A quantidade de material obturador remanescente após utilizar instrumentos ProTaper Retratamento foi similar àquela obtida após repreparo com instrumentos de rotação contínua e reciprocantes e após a IUP $(p>0,05)$. Instrumentos de rotação contínua e reciprocantes proporcionaram similar remoção de material obturador $(p>0,05)$. A maior redução do volume de material obturador foi obtida após utilizar os instrumentos ProTaper Retratamento. Instrumentos de rotação contínua e reciprocantes, assim como a IUP, não reduzíram o volume de material obturador remanescente.

\section{Acknowledgements}

The authors would like to thank FAPESP for the financial support (Grant \#2010/16072-2).

\section{References}

1. Só MV, Saran C, Magro ML, Vier-Pelisser FV, Munhoz M. Efficacy of ProTaper retreatment system in root canals filled with gutta-percha and two endodontic sealers. J Endod 2008;34:1223-1225.

2. Roggendorf $M J$, Legner $M$, Ebert J, Fillery E, Frankenberger R, Friedman S. Micro-CT evaluation of residual material in canals filled with Activ GP or GuttaFlow following removal with NiTi instruments. Int Endod J
2010:43:200-209.

3. Takahashi CM, Cunha RS, Martin AS, Fontana CE, Silveira CF, Silveira Bueno CE. In vitro evaluation of the effectiveness of ProTaper universal rotary retreatment system for gutta-percha removal with or without a solvent. J Endod 2009;35:1580-1583.

4. Ma J, Al-Ashaw AJ, Shen Y, Gao Y, Yang Y, Zhang C, et al. Efficacy of ProTaper Universal Rotary Retreatment system for gutta-percha removal from oval root canals: a micro-computed tomography study. J Endod 2012;38:1516-1520.

5. Hassanloo A, Watson $P$, Finer $Y$, Friedman S. Retreatment efficacy of the Epiphany soft resin obturation system. Int Endod J 2007;40:633-643.

6. Rios M de A, Villela AM, Cunha RS, Velasco RC, De Martin AS, Kato $A S$, et al. Efficacy of 2 reciprocating systems compared with a rotary retreatment system for gutta-percha removal. J Endod 2014; 40:543546.

7. Zuolo AS, Mello JE Jr, Cunha RS, Zuolo ML, Bueno CE. Efficacy of reciprocating and rotary techniques for removing filling material during root canal retreatment. Int Endod J 2013; 46:947-53.

8. Martinho FC, Freitas LF, Nascimento GG, Fernandes AM, Leite FR, Gomes AP, Camões IC. Endodontic retreatment: clinical comparison of reciprocating systems versus rotary system in disinfecting root canals. Clin Oral Investig 2015; 19:1411-1417.

9. Silva EJ, Orlowsky NB, Herrera DR, Machado R, Krebs RL, Coutinho-Filho $T$ de S. Effectiveness of rotatory and reciprocating movements in root canal filling material removal. Braz Oral Res 2015; 29:1-6.

10. Berutti E, Chiandussi G, Paolino DS, Scotti N, Cantatore G, Castellucci A, et al. Canal shaping with WaveOne Primary reciprocating files and ProTaper system: a comparative study. J Endod 2012;38:505-509.

11. van der Sluis LW, Wu MK, Wesselink PR. The evaluation of removal of calcium hydroxide paste from an artificial standardized groove in the apical root canal using different irrigation methodologies. Int Endod $J$ 2007:40:52-7.

12. Wiseman A, Cox TC, Paranjpe A, Flake NM, Cohenca N, Johnson JD. Efficacy of sonic and ultrasonic activation for removal of calcium hydroxide from mesial canals of mandibular molars: a microtomographic study. J Endod 2011;37:235-238.

13. Castagna F, Rizzon P, da Rosa RA, Santini MF, Barreto MS, Duarte MA, et al. Effect of passive ultrassonic instrumentation as a final irrigation protocol on debris and smear layer removal - a SEM analysis. Microsc Res Tech 2013;76:496-502.

14. Cavenago BC, Ordinola-Zapata R, Duarte MA, del Carpio-Perochena $A E$, Villas-Bôas $M H$, Marciano MA, et al.. Efficacy of xylene and passive ultrasonic irrigation on remaining root filling material during retreatment of anatomically complex teeth. Int Endod J 2014; 47:10781083.

15. Fruchi LC, Ordinola-Zapata R, Cavenago BC, Duarte MAH, Bueno CE, De Martin AS. Efficacy of reciprocating instruments for removing filling material in curved canals obturated with a single-cone technique: a micro-computed tomographic analysis. J Endod 2014;40:1000-1004

16. Rechenberg DK, Paqué F. Impact of cross-sectional root canal shape on filled canal volume and remaining root filling material after retreatment. Int Endod J 2013;46:547-555.

17. Kfir A, Abramovitz I, Relles-Bonar S, Baransi B. The effectiveness of a self-adjusting file to remove residual gutta-percha after retreatment with rotary files. Int Endod J 2012;45:386-392.

18. Kenee DM, Allemang JD, Johnson JD, Hellstein J, Nichol BK. A quantitative assessment of efficacy of various calcium hydroxide removal techniques. J Endod 2006;32:563-565.

19. Vilanova WV, Carvalho-Junior JR, Alfredo E, Sousa-Neto MD, SilvaSousa YT. Effect of intracanal irrigants on the bond strength of epoxy resin-based and methacrylate resin-based sealers to root canal walls. Int Endod J 2012;45:42-48.

20. Grischke J, Müller-Heine A, Hülsmann M. The effect of four different irrigation systems in the removal of a root canal sealer. Clin Oral Investig 2014;18:1845-1851. 